\title{
Calculation of the Stiffness in the Roll Tensioning of the Circular Saw Blade
}

\author{
Vo Tung Linh ${ }^{\text {a }}$, and Zang Yong \\ School of Mechanical Engineering, University of Science and Technology Beijing, 100083, China
}

\begin{abstract}
The circular blade has been widely used in some projects such as cutting stone, wood and other projects. Owing to its particularity and wide use, it has an important position in cutting industry. Roll tensioning is considered as an effective method which can be used to improve the stiffness and performance of the circular saw blade. The effect of rolling position and width in the roll tensioning is obvious. In this paper the calculation of the maximum stiffness at different rolling position and width in the rolling were carried out through the finite -element. The results show that three ideal points are found. And when rolling position is $\varnothing 950 \mathrm{~mm}$ and rolling width is $20 \mathrm{~mm}$, the maximum stiffness of the circular saw blade whose minimum deformation is $0.028 \mathrm{~mm}$ is found. The roll tensioning can increase the stiffness of the saw blade. It will provide a theoretical basis and guidance for the actual production.
\end{abstract}

\section{Introduction}

The circular saw blade has been widely used in some projects such as cutting stone, wood and other projects. Owing to its particularity and wide use, it has an important position in cutting industry. The circular saw blade is a typical rotating sheet. Usually the thickness diameter ratio is very small. So the stiffness and stability of the saw blade are poor. Higher dynamical stiffness and stability are required to ensure the safety of processing, cutting precision and outturn rate. It has become a major topic concerned and researched by some scholars at home and abroad[1-3] .

At present, some researches show that a suitable distribution of residual stresses in the prestressed saw blade is better to improve the stability of the blade. It is considered as the most economical and effective method. This method is called as roll tensioning. The roll tensioning is an important technology in the processing of the saw blade. The local plastic deformation which changes the distribution of residual stresses in the saw blade occurs in rolling and hammering. Among these methods, the roll tensioning is recognized as an effective method for tensioning. It has a wide application in the industry. The blade tensioning process was studied by many scholars at home and abroad. R.G.Parker and C.D.Mote.Jr[4] proposed a tensioning method. The tensioning load was perpendicularly put on the edge of the hole. Under the different size of the pressure, number of holes and shape of the hole, the natural frequency of the circular saw blade was studied after rolling. The results showed that it can increase the natural frequency and avoid the excessive adaptation. G.S.Schajer and K.J.Kishimoto[5,6] proposed a heating tensioning method. With the nonuniform heating on the circular saw blade, the temporary tensioning is generated. It can eliminate the dish

\footnotetext{
${ }^{\mathrm{a}}$ Corresponding author : tunglinh77@gmail.com
} 
phenomenon caused by excessive tensioning. N. Nicotetti[7] comprehensively studied roll tensioning by experimental and finite element method. Tangential and normal gages were placed on the saw blade. Distribution of strain is obtained. Y.M.Stakhiev[8] studied the effect of rolling diameter, roller shape and rolling pressure on the tensioning. Stakhiev[9] believed that increasing the tensioning load, tensioning decreases at the initial stage and increases gradually. Y.M.Stakhiev[10] introduced a tensioning machine invented by V. Dunaeva, V. Dunaev, Y. Stakhiev. Its principle is that the pressure is put on the circular saw blade to obtain tensioning through a vibrator. At the same time the vibration sensor is used to detect vibration. G. S. Schajer[11] made a deep research on the roll tensioning, and proposed some methods to improve the rolling defects. And the rolling position and width has a very large impact effect on tensioning processing. But there is little research on rolling position and width. In this paper the calculation of the maximum stiffness at different rolling position and width in the rolling were carried out through the finite - element. It will provide a theoretical basis and guidance for the actual production.

\section{Material model of circular saw blade}

In this paper, the material of the saw blade is $65 \mathrm{Mn}$. According to the relevant information, the mechanical properties of $65 \mathrm{Mn}$ are obtained as seen in Table 1.

Table 1. Mechanical properties of $65 \mathrm{Mn}$.

\begin{tabular}{lcc}
\hline Material & & $65 \mathrm{Mn}$ \\
Density $\left(\mathrm{kg} / \mathrm{m}^{3}\right)$ & $\rho$ & 7810 \\
Elastic modulus $\left(\mathrm{N} / \mathrm{m}^{2}\right)$ & $\mathrm{E}$ & $2.0 \mathrm{E}+11$ \\
Poisson's ratio & $\mathrm{V}$ & 0.3 \\
Shear modulus $(\mathrm{GPa})$ & $\mathrm{G}$ & 82 \\
yield limit $(\mathrm{MPa})$ & $\sigma$ & 800 \\
\hline
\end{tabular}

Owing to the plastic deformation generated in the rolling zone of the saw blade, the stress intensification of the material should be considered in this research. But the strain produced by rolling is very small. Therefore, in this paper the bilinear kinematic hardening criterion (Bkin) can be used to simulate rolling. The stress-strain curve of the material is shown in Figure 1. The yield limit of $65 \mathrm{Mn}$ was $800 \mathrm{Mpa}$, and the shear modulus of $65 \mathrm{Mn}$ was $82 \mathrm{Gpa}$.

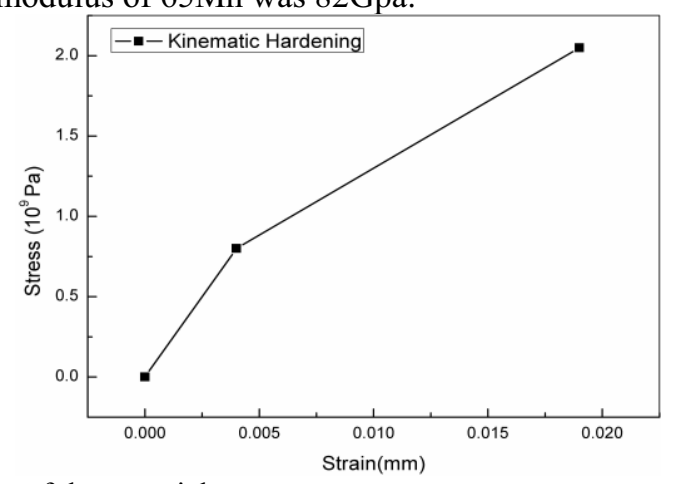

Figure 1. The stress-strain curve of the material.

\section{Calculation of the stiffness of the circular saw blade in roll tensioning}

\subsection{Mesh model}

Mesh model of the saw blade is shown in Fig.2. In the mesh model the hexahedral element is adopted. First, planar element is used to divide flat mesh of the saw blade. Then the flat mesh is extruded to 
generate body mesh. The mesh sensitivity is fine. From Fig. 2 it can be seen that the mesh in the edge and centre of the saw blade is dense. There are 4125 units and 8929 nodes.

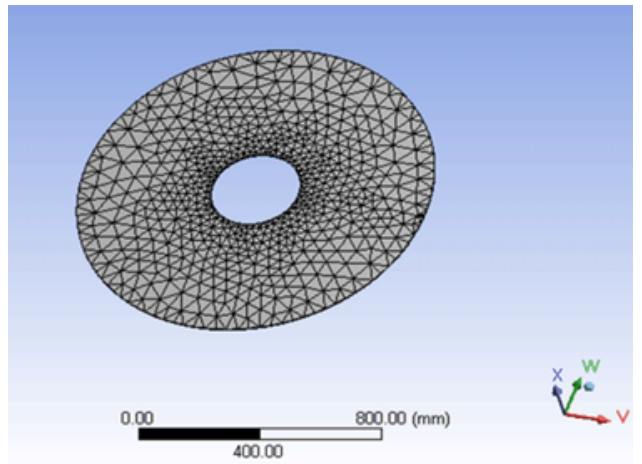

Figure 2. Mesh model of Circular saw blade

\subsection{Results and discussion}

In order to investigate the changes of stiffness after rolling, the explicit dynamic FEM is adopted to analyze rolling model. Through this method the distribution of residual stress after rolling can be accurately obtained. As the initial stress load, the residual stress is introduced in subsequent analysis. Because many various conditions including different rolling position and width are took into account in subsequent analysis. It is time consuming. So the algorithm is not appropriate for this analysis. In order to simplify the calculation, when the effect of rolling position and width on the stiffness of the saw blade are analyzed, rolling pressure is directly load on the saw blade to generate the plastic deformation and the residual stress is introduced. Then radial and tangential loads are put on the circular saw blade to investigate the radial deformation of the circular saw blade. The stiffness can be obtained through calculation. In order to get the changes of the stiffness, three load steps can be done in ANSYS. In the first load step the rolling pressure is directly load on the saw blade to generate the plastic deformation. In the second load step, rolling pressure is removed to solve the distribution of residual stress after rolling. The radial and tangential loads are put on the circular saw blade to investigate the radial deformation of the circular saw blade and calculate the changes of the stiffness in the third load step.

Different plant uses different rolling width. According to the investigation, the rolling width varies from $5 \mathrm{~mm}$ to $20 \mathrm{~mm}$. Rolling position varies from $\varnothing 600 \mathrm{~mm}$ to $\varnothing 1100 \mathrm{~mm}$. Using the finite element ANSYS software, the optimization of rolling position and width of circular saw blade is carried out under $900 \mathrm{MPa}$ pressure. The maximum radial deformation of the saw blade which is the optimization objective is set at the minimum. Fig. 3 shows the result of the optimization. From Fig.3 it can be seen that three optimization points are found. And when rolling position is $\varnothing 950 \mathrm{~mm}$ and rolling width is $20 \mathrm{~mm}$, the maximum stiffness of the circular saw blade whose minimum deformation is $0.028 \mathrm{~mm}$ is found.

\begin{tabular}{|c|c|c|c|c|}
\hline 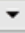 & A & B & c & D \\
\hline 1 & & P2 - XYPlane.D6 & P3 - XYPlane.L5 & P1 - Total Deformation Maximum (mm) \\
\hline 2 & \multicolumn{4}{|c|}{ E Optimization Study } \\
\hline 3 & Objective & No Objective $\mathbf{v}$ & No Objective - & Minimize \\
\hline 4 & Target Value & & $\boldsymbol{v}$ & \\
\hline 5 & Importance & Default & Default & Default \\
\hline 6 & \multicolumn{4}{|c|}{ E GDO Sample Set 1} \\
\hline 7 & Candidate A & - 950 & -20 & 0.028436 \\
\hline 8 & Candidate B & - 910 & -20 & 0.028464 \\
\hline 9 & Candidate C & -870 & -20 & 0.028531 \\
\hline
\end{tabular}

Figure 3. Result of the optimization. 


\section{MATEC Web of Conferences}

Fig.4 shows the distribution of feasible point. In Fig.4 the horizontal coordinate shows the radial deformation of the saw blade. And the longitudinal coordinate show the rolling position. From Fig. 4 it can be seen that when rolling position is $\varnothing 950 \mathrm{~mm}$, the radial deformation of the saw blade is minimal. The minimum deformation is $0.028 \mathrm{~mm}$. When rolling position is $\varnothing 700 \mathrm{~mm}$, the radial deformation of the saw blade is maximal. The maximum deformation is $0.03 \mathrm{~mm}$.

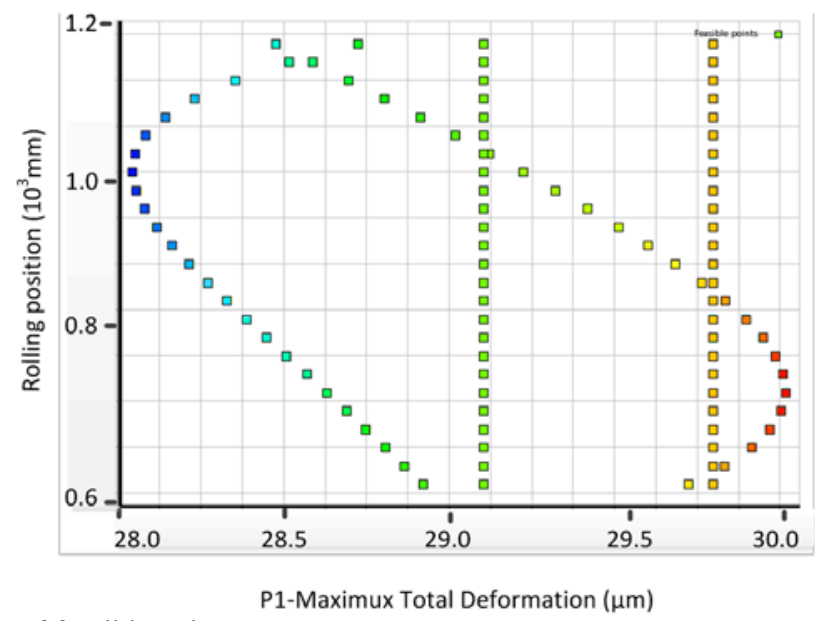

Figure 4. The distribution of feasible point.

Fig.5 shows 3D response of the deformation. In Fig.5 the X-axis shows the rolling position, the Yaxis shows the rolling width and the Z-axis shows the radial deformation of the saw blade. From Fig.5 it can be seen that with the increasing rolling position, the deformation of the circular saw blade increases and then decreases. With increasing of the rolling width, the deformation of the circular saw blade decreases. The results of the calculation will be used for subsequent experiments.

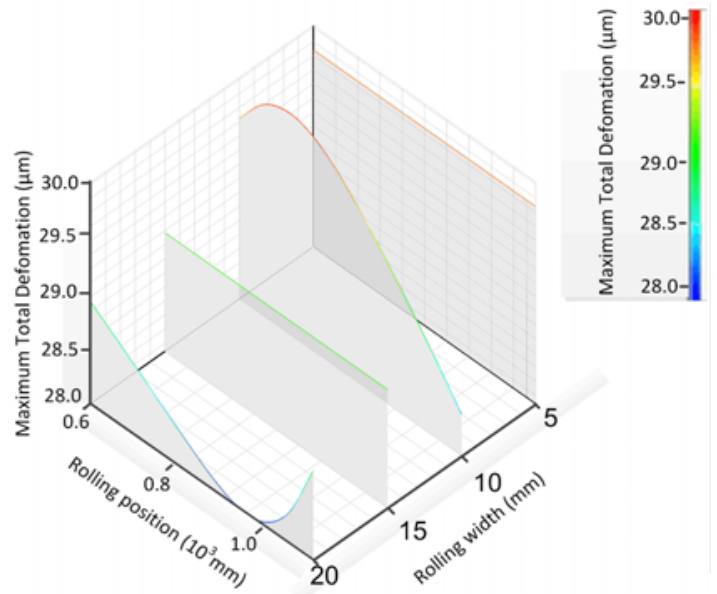

Figure 5.. 3D response of the deformation.

Generally rolling is carried out to increase the stiffness of the circular saw blade. In order to testify the correctness of the above optimization, the radial deformation of the circular saw blade without rolling is analyzed. Fig. 6 shows the deformation of the saw blade without rolling. From Fig. 6 it can be seen that the maximum deformation of the saw blade is $0.03 \mathrm{~mm}$. The maximum deformation of the saw blade without rolling is larger than the maximum deformation of the saw blade with rolling. It indicates the stiffness of the saw blade with rolling is larger than the stiffness of the saw blade without rolling. The roll tensioning can increase the stiffness of the saw blade. 


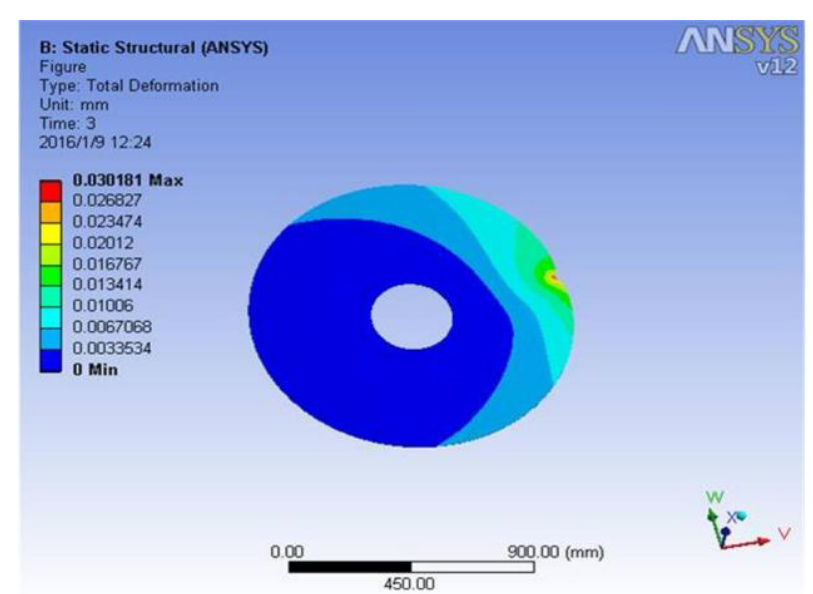

Figure 6. The deformation of the saw blade without rolling.

\section{Conclusions}

In this paper the calculation of the stiffness of the circular saw blade in the rolling were carried out through the finite-element. The results show that three appropriate points are found. And when rolling position is $\varnothing 950 \mathrm{~mm}$ and rolling width is $20 \mathrm{~mm}$, the maximum deformation of the saw blade is $0.028 \mathrm{~mm}$. The maximum deformation of the saw blade without rolling is $0.03 \mathrm{~mm}$. The maximum deformation of the saw blade without rolling is larger than the maximum deformation of the saw blade with rolling. The appropriate roll tensioning can increase the stiffness of the saw blade.

\section{References}

1. B. Gospodaric ${ }^{2}$ B. Buc ${ }^{\nu}$ ar $\bullet$ G. Fajdiga. Active vibration control of circular saw blades. Eur. J. Wood Prod, 73:151 158 (2015)

2. Wen-Tung Chang \& Chih-Hsien Su \& Dong-Xie Guo \& Geo-Ry Tang \& Fang-Jung Shiou. Automated optical inspection for the runout tolerance of circular saw blades. Int J Adv Manuf Technol, 66:565 582 (2013)

3. Mats Ekevad, Luís Cristóvão \& Birger Marklund. Wear of teeth of circular saw blades. Wood Material Science and Engineering, 7: 150 153 (2012)

4. R. G. Parker and C. D. Mote. Jr. Asymmetric tensioning of circular saws.Holz als Roh-und Werkstoff, 47:143 151 (1989)

5. G. S. Schajer. Understanding saw tensioning. Holz als Roh- and Werkstoff, 42:425 430 (1984)

6. G. S. Schajer .North American techniques for circular saw tensioning and leveling: Practical adjustment methods. Holz als Roh- and Werkstoff, 50:153 157 (1992)

7. N. Nicoletti, D. Fendeleur, L. Nilly, M. Renner. Using Finite Elements to model circular saw roll tensioning. Holz als Roh- and Werkstoff, 54:99 104 (1996)

8. Y.M.Stakhiev. Research on circular saws roll tensioning in Russia: Practical adjustment methods. Holz als Roh- and Werkstoff, 57:57 62 (1999)

9. Stakhiev .Y. Cavity oscillation and equilibrium stability loss of flat thin disk irregular heating[J]. Woodworking machine and tool, 2:27 30 (1993)

10. Y.M.Stakhiev. Y.M.Stakhiev. Coordination of saw blade tensioning with rotation speed: myth or reality? Holz Roh Werkst, 62:313 315 (2004)

11. Schajer. G. S, KISHIMOTO.K. J . High -speed circular sawing using temporary tensioning[J]. Holz als Rol-und werkstoff, 54(4) :361 367 (1996) 